\title{
The cloning and characterization of the arom gene of Pneumocystis carinii
}

\author{
Suneale Banerji, ${ }^{1 *}$ Ann E. Wakefield, ${ }^{1}$ Andrew G. Allen, ${ }^{1} \dagger$ Duncan J. Maskell,${ }^{1} \dagger$ \\ Sarah E. Peters ${ }^{1} \ddagger$ and Julian M. Hopkin ${ }^{2}$ \\ ${ }^{1}$ University of Oxford Department of Paediatrics, Molecular Infectious Diseases Group, Institute of Molecular \\ Medicine, John Radcliffe Hospital, Headington, Oxford OX3 9DU, UK \\ ${ }^{2}$ Osler Chest Unit, Churchill Hospital, Oxford OX3 $7 \mathrm{LJ}, U K$
}

(Received 25 May 1993; revised 28 June 1993; accepted 6 July 1993)

\begin{abstract}
The arom gene, encoding a single polypeptide that catalyses five consecutive steps of the pre-chorismate aromatic amino acid biosynthetic pathway, has been cloned from the opportunistic pathogen Pneumocystis carinii. There is a single open reading frame of $\mathbf{4 7 8 8}$ bp which includes an intron of $\mathbf{4 5}$ bp that does not introduce a stop codon into the sequence. Thus, the derived amino acid sequence consists of 1581 residues, which is highly homologous to all fungal AROM proteins studied to date. These data support the view that $P$. carinii is a fungus and imply that its aromatic amino acid biosynthesis is conventionally organized.
\end{abstract}

\section{Introduction}

Pneumocystis carinii is the pathogen responsible for a pneumonia which affects the immunosuppressed and is the principal cause of death amongst AIDS sufferers in Europe and the USA. Despite increased clinical interest little is known about the biology of the organism.

Recent evidence strongly suggests that $P$. carinii is a fungus (Edman et al., 1988; Wakefield et al., 1992; Ympa-Wong et al., 1992), rather than a protozoon. Aromatic amino acid biosynthesis in the fungi is dependent on the pre-chorismate pathway. Steps 2 to 6 of this pathway are catalysed by a single pentafunctional protein called AROM which is encoded by a single gene (Fig. 1). The aromatic amino acid biosynthetic pathway is found in bacteria, plants and lower eukaryotes, but is absent from mammals.

*Author for correspondence. Tel. +44865222344; fax +44865 222626; e-mail SBANERJI@MOLBIOL.OX.AC.UK.

$\dagger$ Present address: Department of Biochemistry, Imperial College of Science, Technology and Medicine, Exhibition Road, London SW7 2AZ, UK.

$\ddagger$ Present address: School of Biological Sciences, Queen Mary and Westfield College, University of London, Mile End Road, London E1 4NS, UK.

Abbreviations: DHQ, 3-dehydroquinate; DHS, 3-dehydroshikimate; EPSPS, 5-enolpyruvylshikimate-3-phosphate synthase.

The GenBank accession number for the sequence reported in this paper is L18918.
The existence of a pentafunctional AROM protein has been demonstrated in Neurospora crassa (Giles et al., 1967) and Schizosaccharomyces pombe (Strauss, 1979). The AROM encoding genes, arom and $A R O 1$, have been cloned from Aspergillus nidulans and Saccharomyces cerevisiae respectively (Charles et al., 1986; Duncan et al., 1987). In plants, the five enzymes are found as three separate polypeptides and one bifunctional protein that contains the 3-dehydroquinate (DHQ) dehydratase and 3-dehydroshikimate (DHS) dehydrogenase activities. The corresponding enzymes from E. coli and other bacteria are monofunctional, encoded by separate genes dispersed around the genome (Bachmann, 1983). The fungal arom locus is thought to have arisen through gene fusions (Hawkins, 1987) as the protein is homologous with the five monofunctional bacterial enzymes, and is made up of functional domains which fold independently or semi-independently.

This paper describes the cloning and characterization of the arom gene from $P$. carinii. The strategy employed in cloning the gene used mixed primer polymerase chain reaction (PCR). The sequences of the mixed primers were derived from the back-translation of conserved blocks of amino acids from the 5-enolpyruvylshikimate3-phosphate synthase (EPSPS) enzymes from other organisms, with bias toward the fungal sequences.

\section{Methods}

Isolation of $P$. carinii DNA. P. carinii infection was induced in Sprague-Dawley rats by steroid immunosuppression (Wakefield $e t$ al., 1988) and the organisms were purified from infected rat lung using the 
(a)
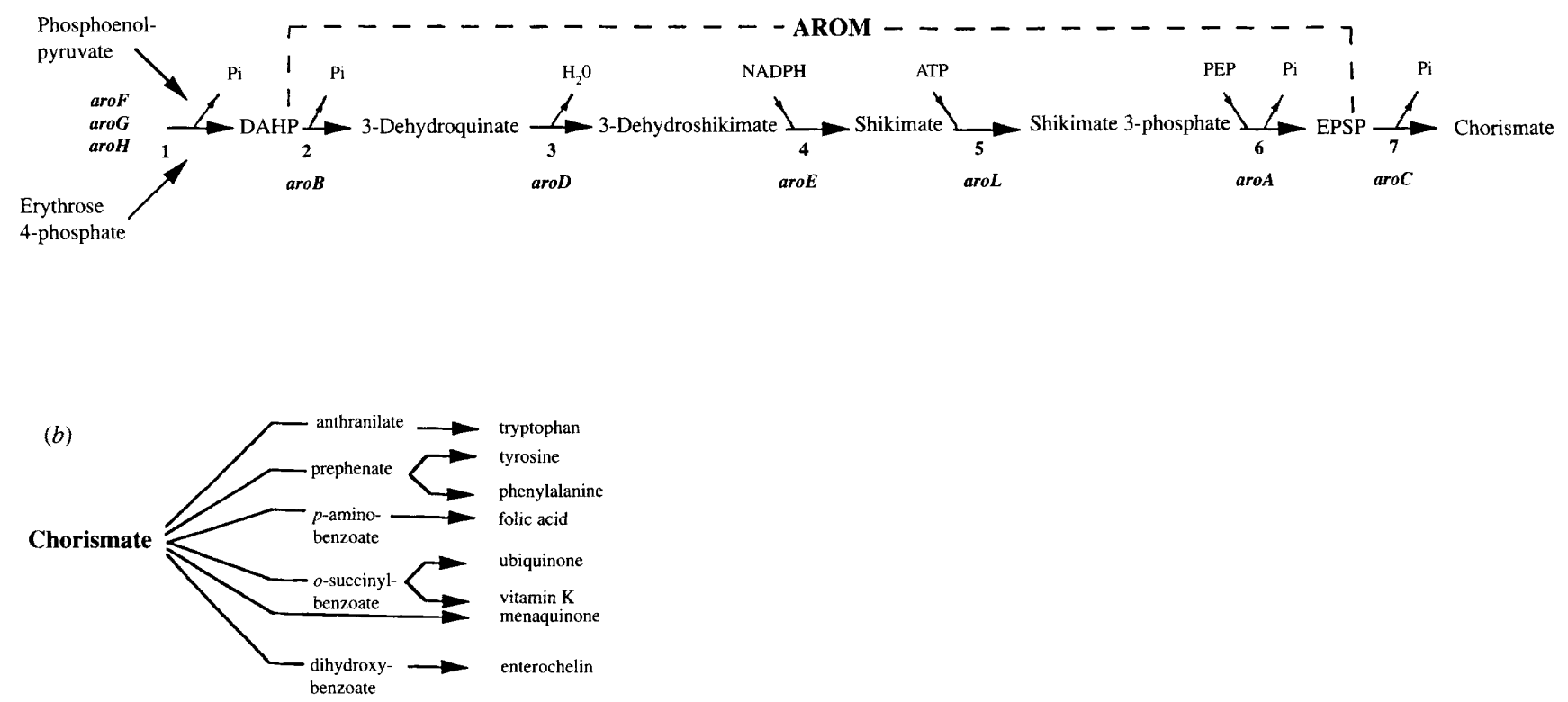

Fig. 1. (a) Reactions of the early common (pre-chorismate) pathway of aromatic amino acid biosynthesis. The enzymes catalysing these steps are: (1) 3-deoxy-D-arabino-heptulosonic acid-7-phosphate synthase (EC 4.1.2.15); (2) 3-dehydroquinate synthase (EC 4.6.1.3); (3) 3-dehydroquinase (EC 4.2.1.10); (4) shikimate dehydrogenase (EC 1.1.1.25); (5) shikimate kinase (EC 2.7.1.71); (6) 5enolpyruvylshikimate-3-phosphate synthase (EC 2.5.1.19); (7) chorismate synthase (EC 4.6.1.4). DAHP, 3-deoxy-D-arabinoheptulosonic acid 7-phosphate; EPSP, 5-enolpyruvylshikimate 3-phosphate. The AROM pentafunctional enzyme catalyses steps 2 to 6 of the pathway as shown. The gene symbols shown are from E. coli. (b) Use of chorismate in the biosynthesis of aromatic compounds.

method described by Peters et al. (1992). Rat-derived $P$. carinii material was digested with proteinase $\mathrm{K}\left(0.5 \mathrm{mg} \mathrm{m}^{-1}\right)$ in the presence of $0.2 \%$ SDS at $50^{\circ} \mathrm{C}$ for $16 \mathrm{~h}$. Genomic DNA was isolated by phenol extraction followed by ethanol precipitation.

Oligonucleotides and PCR amplification. Two synthetic mixed oligonucleotides were made, AroPCR 1 and AroPCR6, the sequences of which were derived from the back-translation of conserved amino acid motifs from the bacterial and plant EPSPS sequences and the EPSPS domains from the fungal AROM proteins. The sequence of AroPCR1 was derived from the peptide LGNAGTA (residues 496-502 from the $S$. cerevisiae AROM protein) and the nucleotide sequence was 5'${ }_{\mathrm{C}}^{\mathrm{T}}$ TNGGNAA ${ }_{\mathrm{C}}^{\mathrm{T}} \mathrm{GCNGGNACNGC}\left(5^{\prime}\right.$ to $3^{\prime}$ on the coding strand). The sequence of AroPCR6 was based on the peptide LMCAPYA (which is conserved in the fungi, residues 588-594 from $S$. cerevisiae AROM

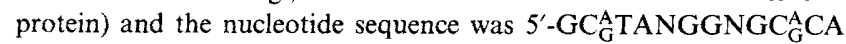
CATNA ( $5^{\prime}$ to $3^{\prime}$ on the non-coding strand). The final concentrations for the reagents in the amplification reactions were: $10 \mathrm{~mm}$-Tris $/ \mathrm{HCl}$, $50 \mathrm{~mm}-\mathrm{KCl}, 0.4 \mathrm{~mm}$-dNTPs, $0.1 \mathrm{mg}$ gelatin $\mathrm{ml}^{-1}, 0.025$ units Taq DNA polymerase (Boehringer Mannheim) $\mu^{-1}$ and the concentration of $\mathrm{MgCl}_{2}$ was varied between 1.5 and $4 \mathrm{~mm}$. The PCR reaction cycle consisted of: $94^{\circ} \mathrm{C}$ for $1.5 \mathrm{~min}, 48^{\circ} \mathrm{C}$ for $1.5 \mathrm{~min}$ and $72{ }^{\circ} \mathrm{C}$ for $2 \mathrm{~min}$, and was repeated 40 times.
Two further oligonucleotides were made from specific $P$. carinii sequences. These were Aroseq1 (5'-GCACTTATAGAGGATTGGC) and Aro 15 (5'-CATCAATAGAAACAATGTGAGC). The positions of these primers are illustrated in Fig. 2. The conditions for the PCR amplification cycles were as described previously and the concentration of $\mathrm{MgCl}_{2}$ was $3 \mathrm{mM}$. These primers were used in PCR experiments in which the template was $P$. carinii genomic DNA and in other experiments in which a $P$. carinii cDNA library served as template. The cDNA library was obtained from Dr C. J. Delves (Department of Molecular Sciences, The Wellcome Laboratories, Beckenham, UK). The construction of this library was described by Dyer et al. (1992).

Resolution of PCR products by PAGE. A $6 \%(\mathrm{w} / \mathrm{v})$ non-denaturing polyacrylamide gel $(29: 1$, acrylamide/bisacrylamide) was used for separation of PCR products. DNA was visualized by staining the gel with ethidium bromide $\left(1 \mu \mathrm{g} \mathrm{ml}^{-1}\right)$ and viewed under UV illumination. Candidate bands were excised from the gel and the DNA was extracted using the crush and soak method described by Sambrook et al. (1989). The DNA was then treated with Klenow DNA polymerase followed by T4 polynucleotide kinase to allow ligation into EcoRV digested and phosphatase treated pBluescriptII (Stratagene).

Sequencing. Recombinant plasmids were sequenced using the dideoxy chain termination method (Sanger et al., 1977) using T7 DNA

Fig. 2 (following three pages). Complete nucleotide sequence of the $P$. carinii arom gene and translation of the ORF into the amino acid sequence. The underlined motifs in the $5^{\prime}$ untranslated regions show a potential TATA box (TATAA) and a ribosome binding site (GAAG) immediately before the ATG translation initiation codon. The underlined sequence in the $3^{\prime}$ untranslated sequence may constitute a polyadenylation signal (AATAA). The region marked IVS indicates the nucleotides that represent an intron. The sequence from which the oligonucleotide Aroseq 1 was derived is indicated $(\longrightarrow)$ and the sequence from which Arol 5 was derived is also shown ( $-(-—)$. Arol 5 was from the anti-sense strand. The sequence between -233 and -225 is potentially a GCN4 binding site. 
GCN4

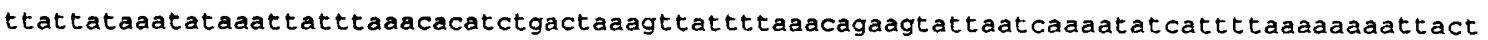

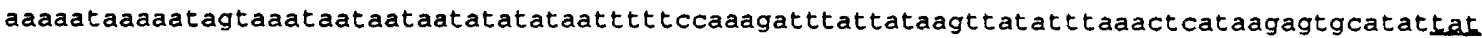
gat taagcataaagacttectcatctaaaattgagaaatacataaat tattcatat taaactgctttcttaatgaaggaATGAAG

GAAATTATCAAACTTAGTATTTTAGGGAAAGATTCTATTCATATTGGGCTTCACTTATGGCCACATATAACTAATGAACTATTTACATGT

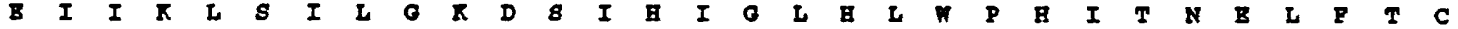

ATATTTTCTCCAACATATGTAATCATTACGGATTCAAATATTGAAACCTTATATATTCCTAGTTTCAAAACATATTTCATTTCTATGGCA

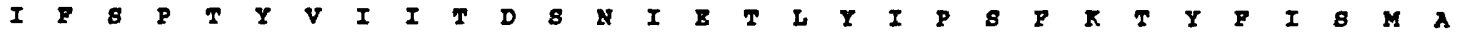
Aroneg1 AAACAAAGATCTATTAATTCTCGTCTTTTATTTTTTACAATTCTCCTGGAGAAAAATCAAAATCAAGAAAAACAAAAGCACTTATAGAG

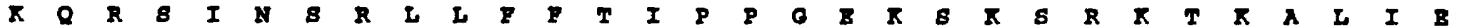

GATTGGCTTTTATCAGAAAAATGCACAAGAGATACTGTTATAATAGCTATAGGGGGCGGTGTTATAGGCGATCTCGTAGGTTATGTCTCT

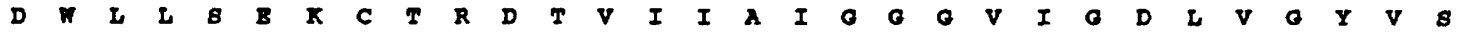

GCAACATTTATGAGAGGAGTTCGTTTTATTCAAATTCCTACAACTCTTTTAGCTATGGTAGATTCATCTATTGGAGGGAAAAATTCTATA

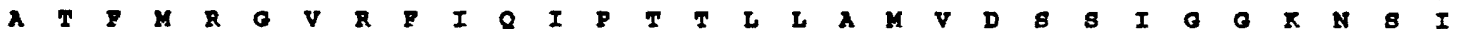




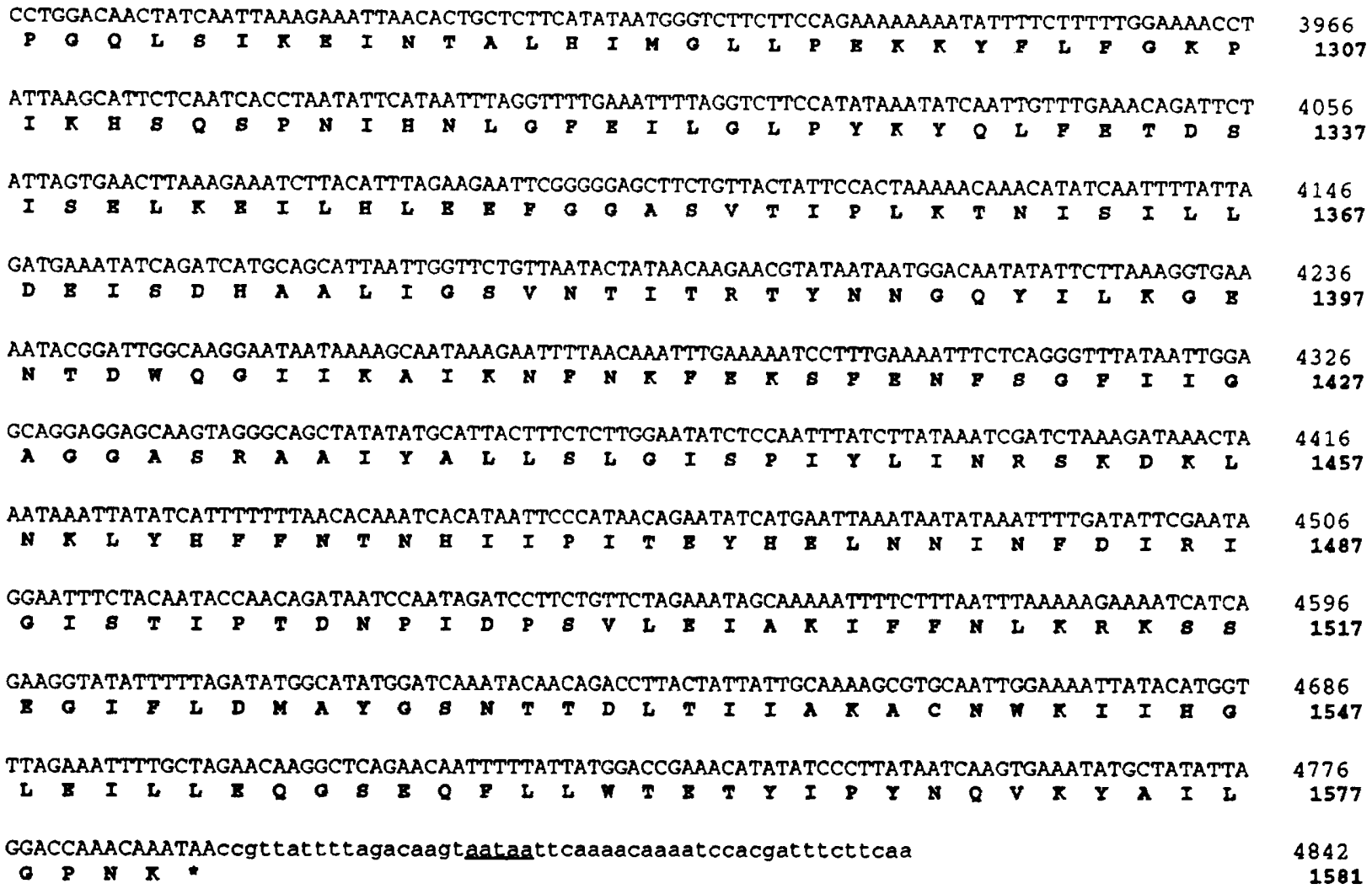

polymerase (Pharmacia) and the protocol described by Tabor \& Richardson (1987). Single stranded template was generated using alkaline denaturation (Chen \& Seeburg, 1985). The University of Wisconsin Genetics Computer Group (UWGCG) programs (Devereux et al., 1984) were used in the analysis of sequence data

Construction of a rat-derived $P$. carinii genomic library. P. carinii genomic DNA was partially digested with the restriction enzyme $M b o I$ and fragments between 23 and $9 \mathrm{kbp}$ were size selected following electrophoresis on a $0.7 \%$ agarose gel (SeaPlaque-GTG from FMC). The gel slice was treated with agarase (Boehringer) to digest the agarose, releasing the $M b o I$ fragments which were then ligated into phosphatase treated $\lambda$ EMBL3 arms which had been prepared by digestion with $B a m \mathrm{HI}$. The ligation was packaged using the Packagene (Promega) system followed by transfection into the $E$. coli host strain LE392. A total of $1.5 \times 10^{4}$ plaques were screened by hybridization using the $300 \mathrm{bp}$ cloned section of the putative $P$. carinii arom locus.

Pulsed field gel electrophoresis. Agarose gel blocks were prepared by adding $P$. carinii organisms (a mixture of cysts and trophozoites) in $1 \mathrm{ml}$ of phosphate-buffered saline (PBS; $0.15 \mathrm{M}-\mathrm{NaCl}, 0.016 \mathrm{M}-$ $\left.\mathrm{Na}_{2} \mathrm{HPO}_{4}, 0.004 \mathrm{M}-\mathrm{NaH}_{2} \mathrm{PO}_{4}, \mathrm{pH} 7 \cdot 3\right)$ to $1 \mathrm{ml}$ of molten agarose ( $2 \%$, $\mathrm{w} / \mathrm{v}$, SeaPlaque-GTG in $125 \mathrm{~mm}$-EDTA). The blocks were cast in a Bio-Rad block former. Solidified blocks were incubated in $500 \mathrm{~mm}-$ EDTA (pH 8), $1 \% N$-laurylsarcosine and $1 \mathrm{mg}^{\circ}$ proteinase $\mathrm{K} \mathrm{ml}^{-1}$ at $50{ }^{\circ} \mathrm{C}$ for $48 \mathrm{~h}$. Pulsed field gel electrophoresis was performed using a CHEF (contour clamped homogeneous electric field) DRII (Bio-Rad) system. $P$. carinii chromosomes were separated by electrophoresis on a $0.9 \%$ SeaKem-GTG (FMC) in $0.5 \times$ TBE $(1 \times$ TBE is $0.089 \mathrm{M}$-Tris base, $0.089 \mathrm{M}$-boric acid, $0.002 \mathrm{M}$-EDTA) for $48 \mathrm{~h}$ at $180 \mathrm{~V}$ in $0.5 \times \mathrm{TBE}$ with an initial switching time of $10 \mathrm{~s}$ increasing to a final switching time of $40 \mathrm{~s}$. Gels were stained with ethidium bromide and photographed under UV illumination. Transfer to nylon membrane was preceded by depurination in $0.25 \mathrm{M}-\mathrm{HCl}$ for $30 \mathrm{~min}$, followed by denaturation and neutralization as described by Sambrook et al. (1989). DNA hybridization was carried out in $25 \%(\mathrm{v} / \mathrm{v})$ formamide at $42{ }^{\circ} \mathrm{C}$ and the filter was then washed at $55^{\circ} \mathrm{C}$ in $1 \times \operatorname{SSC}(1 \times \mathrm{SSC}$ is $0.15 \mathrm{M}-\mathrm{NaCl}, 0.015 \mathrm{M}-$ sodium citrate, $\mathrm{pH} 7$ ) and $0.1 \%$ SDS.

In situ hybridization. A probe which consisted of the cloned EPSPS coding region from $A$. nidulans (a gift from $\mathrm{Dr}$ A. R. Hawkins, University of Newcastle upon Tyne, UK) was labelled with biotin 16dUTP (Boehringer) using the random prime method (Amersham Multiprime kit). A cloned section of the putative $P$. carinii arom locus was labelled with biotin 16-dUTP by use of PCR, according to the method of Emanuel (1991). Sections were taken from a formalin fixed, paraffin embedded $P$. carinii infected rat lung onto silane coated slides. The sections were treated with proteinase $\mathrm{K}\left(0.5 \mathrm{mg} \mathrm{m}^{-1}\right)$ for $30 \mathrm{~min}$ at $37{ }^{\circ} \mathrm{C}$ to expose the DNA in the sample. The hybridization and subsequent detection were carried as described by Burns et al. (1987). The stringent wash was $1 \times \mathrm{SSC}$ at $55^{\circ} \mathrm{C}$.

\section{Results and Discussion}

\section{PCR amplification using mixed oligonucleotides}

The mixed oligonucleotide primers AroPCR 1 and AroPCR6, derived from blocks of highly conserved amino acids from EPSPS sequences, were used to amplify a section of the $P$. carinii gene coding for EPSPS from genomic DNA. The high level of degeneracy of the primers and the contamination of $P$. carinii DNA template with rat DNA resulted in the generation of numerous products around the expected size (about $300 \mathrm{bp}$ ) as determined by agarose gel electrophoresis. 
Thus, a $6 \%$ polyacrylamide gel was run to enable discrete bands in the $300 \mathrm{bp}$ size range to be resolved. DNA from these bands was cloned and sequenced. The deduced amino acid sequence of one of the cloned products was very similar to published EPSPS sequences in the region between the sites of the mixed primers.

\section{Isolation of a bacteriophage $\lambda$ clone carrying the $P$. carinii arom locus}

About $1.5 \times 10^{4}$ plaques from an unamplified $P$. carinii genomic library constructed in $\lambda$ EMBL 3 were screened with the cloned portion of the $P$. carinii EPSPS coding gene generated by the mixed oligonucleotide PCR. One plaque gave a positive hybridization signal. This plaque was purified and replated, and the progeny phage were again positive after hybridization. One of the resultant plaques was picked, named $\lambda$ Pcaro, and the DNA was extracted for further analysis. Digestion of $\lambda$ Pcaro with SalI released an insert of about $12 \mathrm{~kb}$ which was gel purified then digested with $X b a \mathrm{I}$ generating fragments which were cloned into pBluescriptII. One of these subclones contained a $6.5 \mathrm{~kb}$ insert and was named pSB30 and another, pSB31, contained a $5.5 \mathrm{~kb}$ insert, the result of incomplete digestion with $\mathrm{XbaI}$.

\section{Sequencing of the P. carinii arom locus}

The insert of pSB31, which hybridized to the $300 \mathrm{bp}$ cloned section of the EPSPS gene, was sequenced entirely on both strands, revealing an open reading frame (ORF) of about $4 \mathrm{~kb}$ with the $\mathrm{N}$-terminal region of the putative protein absent. The deduced amino acid sequence from this ORF was homologous to the AROM proteins of $S$. cerevisiae and $A$. nidulans, and by analogy with these sequences it was determined that about $700 \mathrm{bp}$ of coding sequence was missing from the $5^{\prime}$ end of the locus. A section of pSB30 was sequenced and a putative ATG initiation codon was identified. Amplification from $P$. carinii genomic template with the primers Aroseq1 and Aro15 generated a $\sim 550$ bp product which was cloned and sequenced, showing that the inserts of pSB30 and pSB31 were contiguous. The complete nucleotide sequence of the $P$. carinii arom locus and the deduced amino acid sequence are shown in Fig. 2. The ORF appears to consist of $4788 \mathrm{bp}$ of nucleotide sequence coding for a peptide of 1596 residues. However, examination of the alignment of the amino acid sequence of the $P$. carinii protein with those of $S$. cerevisiae and $A$. nidulans and a composite of the sequences of the five monofunctional enzymes from E. coli (Fig. 3) indicated that an intron of $45 \mathrm{bp}$ could have been present in the DHQ synthase domain. This was confirmed experimentally through amplification from cDNA template using the primers Aroseq1 and Aro15, resulting in a product of $\sim 500 \mathrm{bp}$ which was cloned and sequenced. The dinucleotide GT (nucleotide positions 583-584) is at the $5^{\prime}$ splice site within the intron and AG (nucleotide positions $626-627$ ) is at the $3^{\prime}$ border. There is a polypyrimidine tract near the $3^{\prime}$ end of the intron and a sequence (YTRAT) that has been identified as a putative lariat forming motif in other $P$. carinii intervening sequences (Zhang \& Stringer, 1993) is present. The occurrence of small introns has been reported in other $P$. carinii genes (Edman et al., 1989 b; Volpe et al., 1992).

The coding sequence of the arom locus is highly AT rich $(70.5 \%)$ and $85 \%$ of the codons contain an A or a $\mathrm{T}$ in the third position. These data agree well with the base composition from other $P$. carinii genes that have been sequenced (Edman et al., 1989a; Kovacs et al., 1993). The $5^{\prime}$ untranslated region contains the sequence TATAA (located at -86 to -82 relative to the $5^{\prime}$ methionine codon), which is a good match for the consensus TATA box. There is also a possible ribosome binding site GAAG at nucleotide positions -5 to -2 . At nucleotides $4810-4814$ the sequence AATAA is a close match for the consensus polyadenylation signal. A further feature of the nucleotide sequence is the presence of a putative GCN4 binding site about 230 bp upstream of the $5^{\prime}$ methionine. The optimum sequence for this motif, usually located at $100-600 \mathrm{bp}$ upstream of the transcriptional start site, is the palindrome $\operatorname{ATGA}(\mathrm{C} /$ G)TCAT, but the sequence found upstream of the $P$. carinii arom locus (CTGACTAAA) shows conservation of the essential bases. The binding of GCN4 to its target sites mediates the 'general amino acid control' mechanism of S. cerevisiae in which starvation for a particular amino acid can lead to the up-regulation of expression of more than 30 genes involved in amino acid biosynthesis (Fink, 1986). The AROI (AROM encoding) locus of $S$.

Fig. 3 (following three pages). Comparison of the amino acid sequences from the A. nidulans (Anarom), S. cerevisiae (Scarom), and $P$. carinii (Pcarom) AROM enzymes and also a composite of the E. coli monofunctional enzymes which have been arranged in the following order: DHQ synthase (residues 1-363) (Millar \& Coggins, 1986); EPSP synthase (364-789) (Duncan et al., 1984); shikimate kinase (790-963) (Millar et al., 1986); DHQ dehydratase (964-1215) and shikimate dehydrogenase (1216-1487) (Anton \& Coggins, 1988). The sequence of DHQ dehydratase has been amended from that originally published (Duncan et al., 1986) following the corrections specified by Chaudhuri et al. (1991). The sequence of the A. nidulans qut $R$ protein (Hawkins et al., 1992) is also shown in the alignment (labelled Anqutr). 
Pcarom

Anarom

Ecaro

Anqutr

Pcarom

Anarom

Scarom

Ecaro

Pcarom

Anarom

Scarom

Ecaro

Anqutr

Pcarom Anarom Scarom

Ecaro

Anqutr

Pcarom

Anarom

Scarom

Ecaro

Anqut

Pcarom

Anarom

Scarom

Ecaro

Anqutr

Pcarom

Anarom

Scarom

Ecaro

Anqutr

Pcarom

Anarom

Scarom

Ecaro

Anqutr

Pcarom

Anarom

Scarom

Ecaro

Anquer

Pcarom

Anarom

Scarom

Ecaro

Anqutr

Pcarom Anarom

Scarom

Ecaro

Anquer

Pcarom

Anarom

Scarom

Ecaro

Anqutr

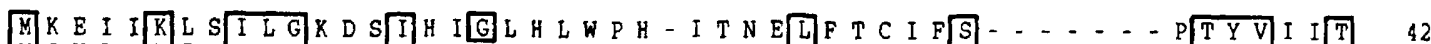
$M$ S N P T T K I S I L G R E S I I A D F G L W R N Y V A K D L I S D C S S - . . . . T T Y Y V L V T

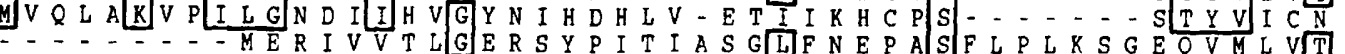
$\ldots \ldots \ldots \ldots \ldots \ldots \ldots \ldots \ldots$

DSNIETLYIDSFKT Y I S A A R R S NSRLLFF T IPRGEKSKSRKTKALE

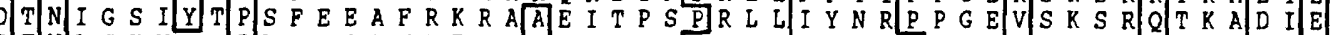

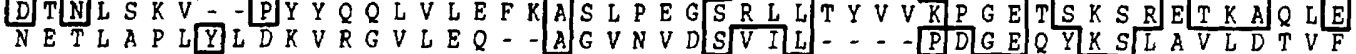

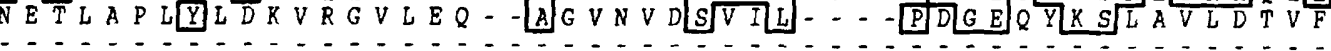

DWLLSEX - - CTRDTVI I A GGVIGDDVGYUSATFMRGVRFIRIPTTILA 140 D WM L S O N P P C C G R D T V V V I A A D. Y L L V E - - G C T T R D T V M V A I G G G V I G D M I G F V A S T F M R G V R V V Q $Q$ V P T T G L L A

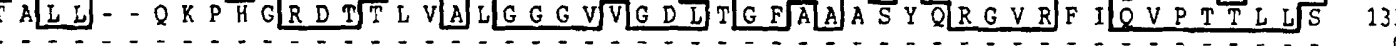

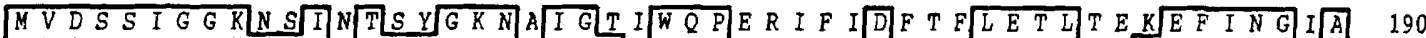

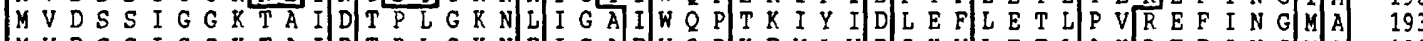

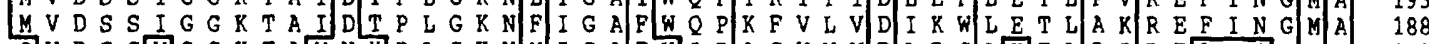

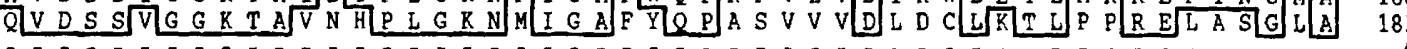

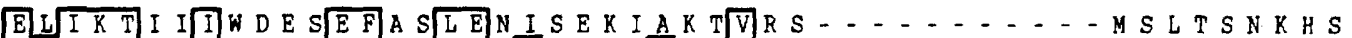

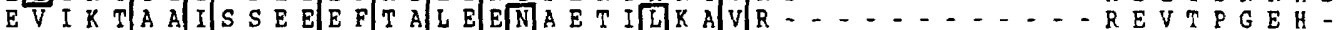
E V I K T. A C I W N A DLE F T R L E S N A S L F L N VLV N G A K N V K V T N Q L T N E I D E I S N T $E \vee I$ Y $G$ I I I L D G A F

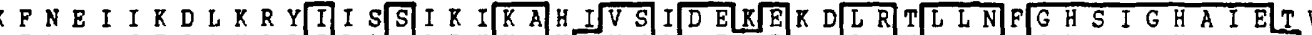

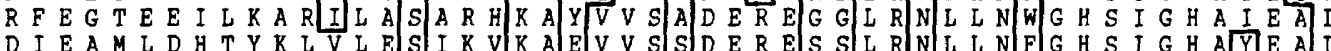
....-. - M A Y C C T R R C C E L K A E E V V A A

279

280

288

256

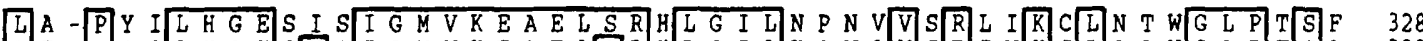
L T - P Q I L H G E CIVA I G V VR E A E L A R HL G I L K G V A V S R I V K C L A A Y G L P T S L 329

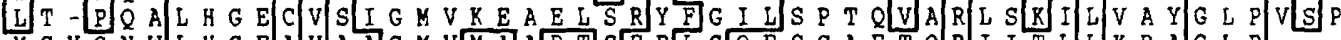

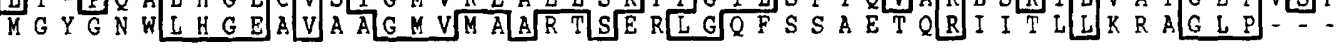

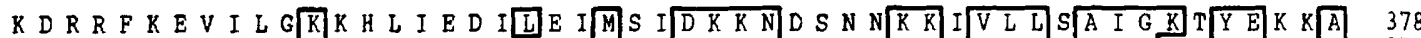

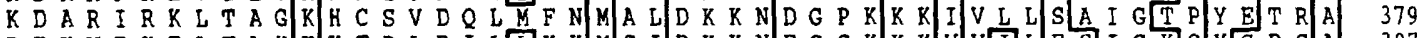

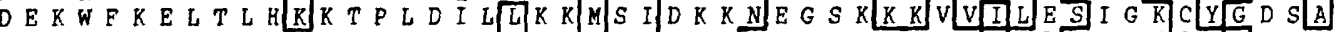

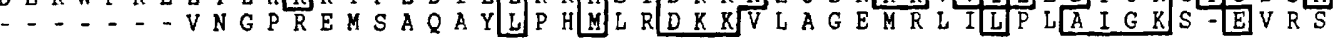

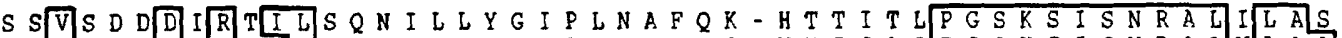
$S$ VVA N E D I R V V L A P S I E V H - - P G V A H S S - N V I C A P P G S K S I S N RA L V L A A Q F V V S D ELD L R F I I T D E T L V Y P F K D I P A D Q - QKVVVI P P G SKS I S N R A L I L A A

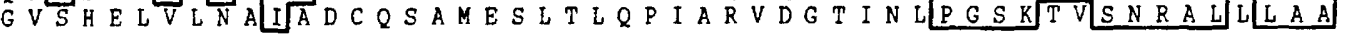

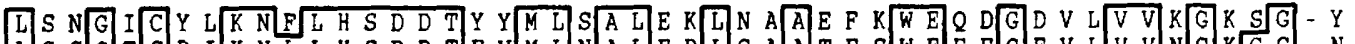

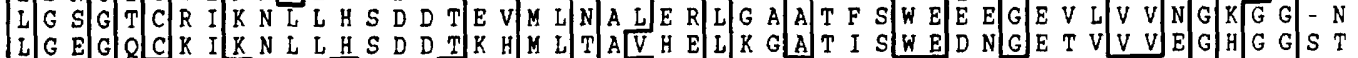

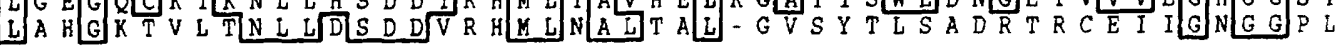

DEN P Q E LYLGNSGTTARFLTS I T TDVQPNS RENHLILTGS NRMKQRPIO $L$ L

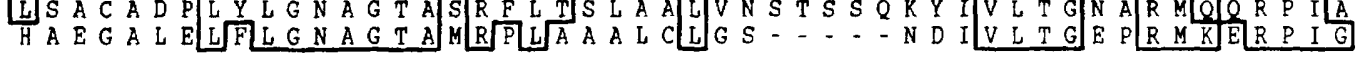

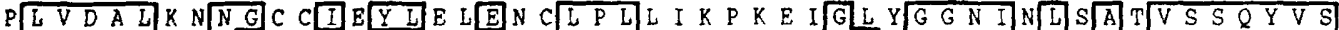
576

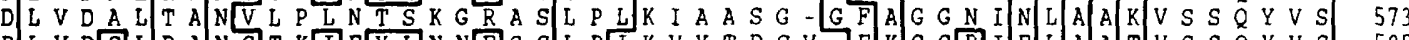

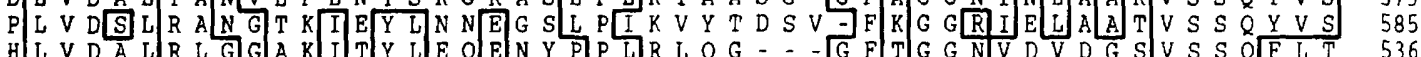
$\begin{array}{lll}L & & \end{array}$ 
Pcarom

Anarom

Scarom

Ecaro

Anqutr

S L L M C C S P

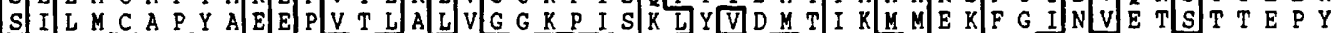
$A$ L L M TLA DA

Pcarom

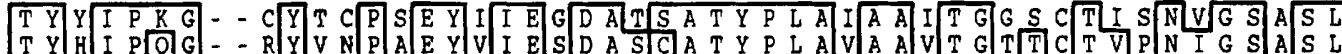

Anarom

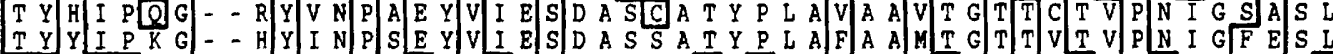

Ecaro

Anqutr

Pcarom

Anarom

Scarom

Ecaro

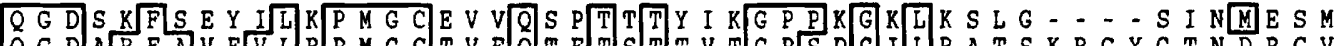

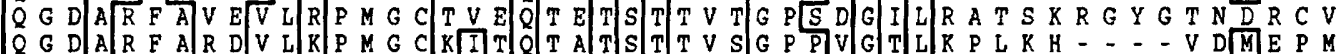
$0 G D I R F A$ - D V L E R M G A T I CW G D D . Y I SCTR R E L A I D . . . M D M N H I

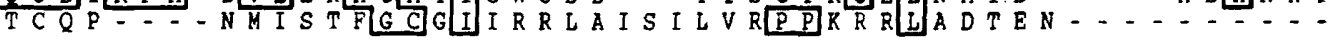

635

Pcarom

Anarom

Scarom

Ecaro

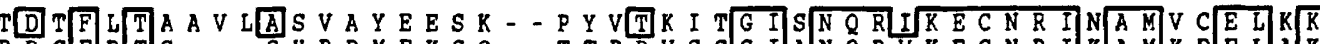

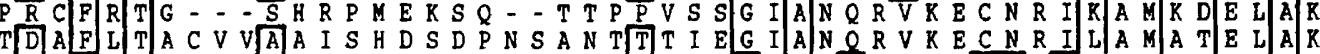

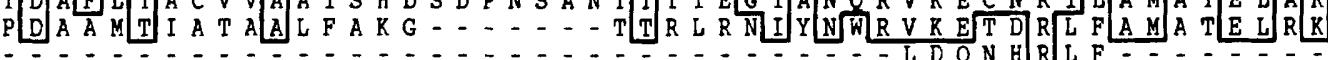

674

683

632

Anqutr

Pcarom

Anarom

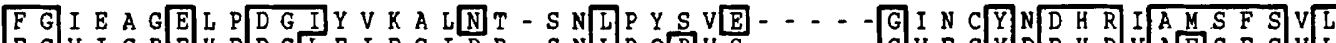

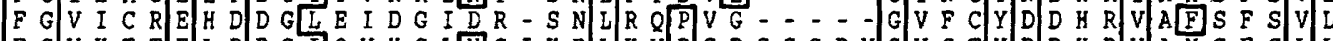
F G V K T T E L P D G T O V H G L圆S I K DLLK V P S D S S G P VLGV C T Y D D H R V A M S F S LLL

Ecaro

Anqutr

Pcarom

Anarom

Scarom

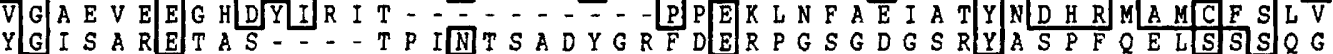

720

721

673

Ecaro

ACI - . - . - S S K PTTTIDKA C N KTWPYWWDI回NSTFKVQMKGI国F D $S D V-2$. AGG V N S Q N E R D E V A N P V R I L E R H C T G K T W P G W W D V L H S E L G A K L D G A

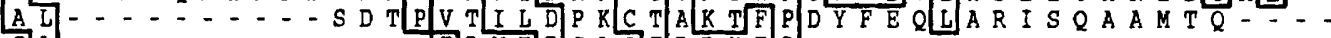

Anqut $r$

Pcarom

Anarom

Scarom

Ecaro

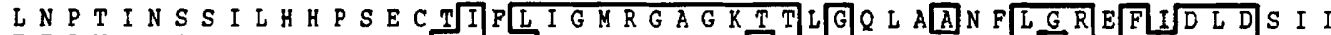

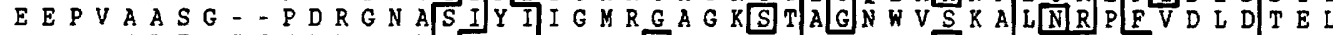
- - - P L E C T SKK N S K KLSVVIJ G M R A A G R T T I SKW C A S A L G Y K D V D L D E L F .

Pcarom

Anarom

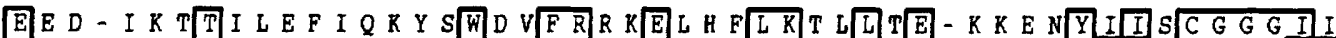

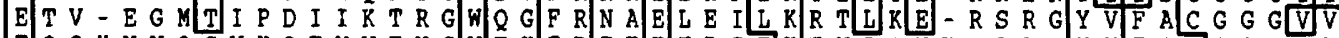

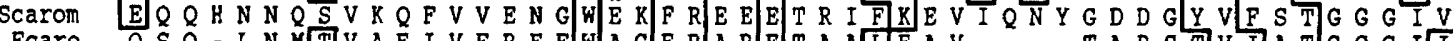

Ecaro

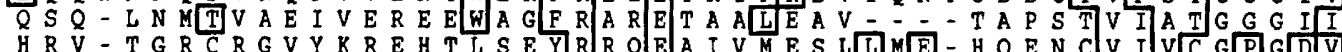

Pcarom

Scarom

Ecaro

Anqutr

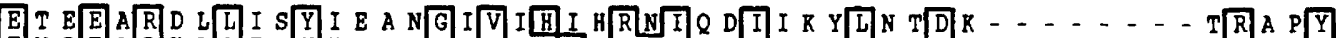

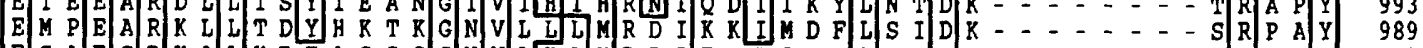
E S ALE S R K A L K D F A S S G G Y V L L H L H R D I E E T I V F L $Q$ S D D P - . . . . . S R P A Y 1015 LT EF N R H FM- - - Q N NGIVVYLCAPVS V L N R L Q A A P E E D L R P T L T GK P L 917

Pcarom

Anarom

Scarom

Ecaro

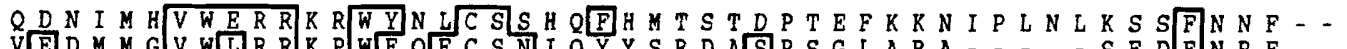
VED M M GV WRR R R P WFOE C S N I QYY S R D A SP S G L A R A - - - S E D F N R F - - 1032

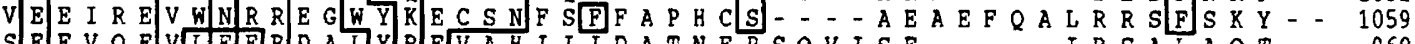

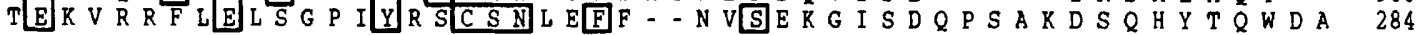

Pcarom

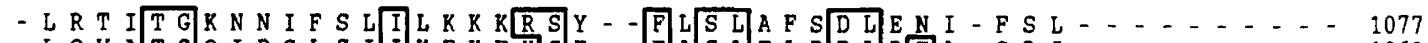

- L Q V A T G Q I D S L S I I K E K E ⿹ S F - - F A S L T L P D L R E A - G D I - . - . - . 1068

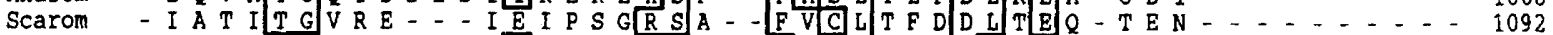

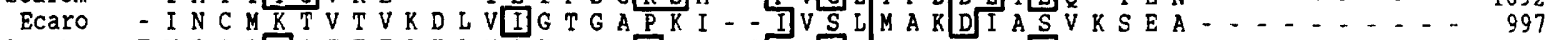

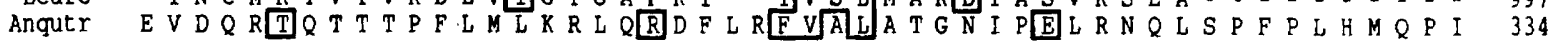

Pcarom

Anarom

Scarom

Ecaro

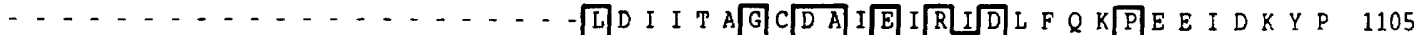
烈

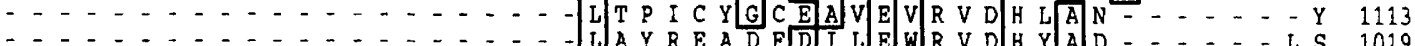

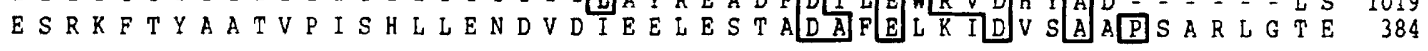


Pcarom Anarom

carom

Ecaro

Anqutr

Pcarom

Anarom

Scarom

Ecaro

Anqut r

Pcarom

Anarom

Scarom

Ecaro

Anqut r

Pcarom

Anarom

Ecaro

Anqut $r$

Pcarom Anarom Scarom

Ecaro

Anqut $r$

Pcarom

Anarom

Scarom

Ecaro

Anqut $r$

Pcarom

Anarom

Scarom

Ecaro

Anqutr

Pcarom

Anarom

Scarom

Ecaro

Anqutr

Pcarom

Anarom

Scarom

Ecaro

Anqutr

Pcarom

Anarom

Scarom

Ecaro

Anqutr

Pcarom

Anarom

Scarom

Ecaro

Anqut r

Pcarom

Anarom

Scarom

Ecaro

Anqutr
S- - LEYIAEKIF LLROKT - S L PLIYTLRTTN HGGSTLSSEKKL-AK EYIL 1151

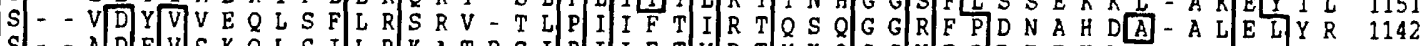

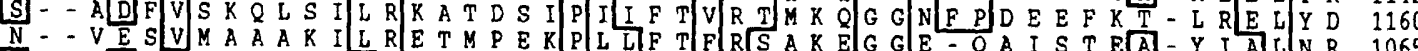

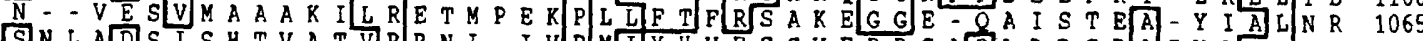

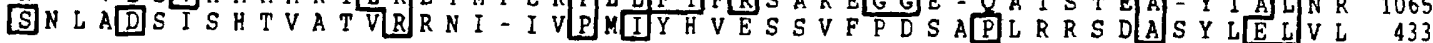

HGAKWG-FEFLDIEDDI A SELFKTIN - - N SWPYTKITASY用N I E K P I - ST 1197 LAF R S G - C E F V D LDD I A F P EDDM L R A V T - - E M K G F S K I I A S H H D P K G E L - S I A L K N G - VLE E L D L E D T L P T D I Q Y E V I - - N K R G N T K I I G S H $A$ A I D S G L V D D I D L E L F T G D D Q V K E T V A Y A H A H D V K V V V M S S H

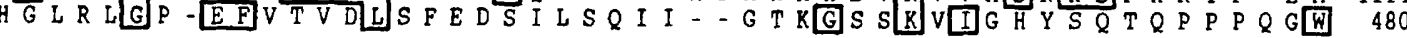

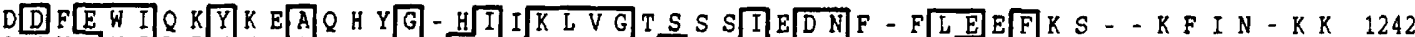

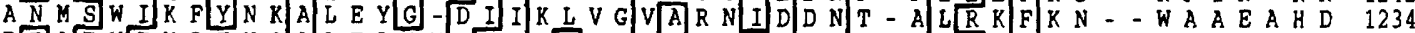

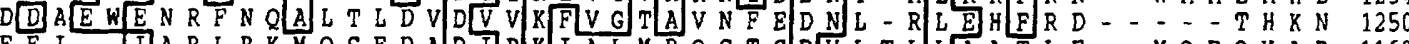

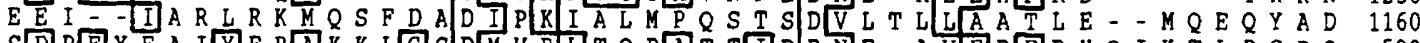
SDP国YEA I

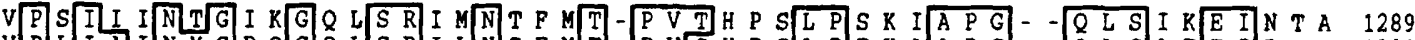

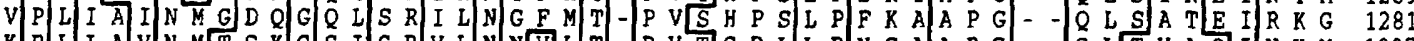

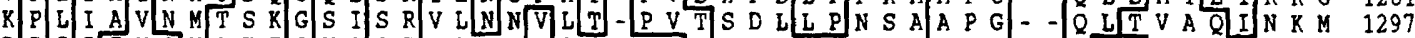
R P I IT M S B A K T G V I S R L A G E V F G S A A T F G A V K R A SLA P G - LOTSV N D L R T V 1208

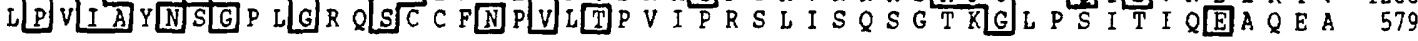

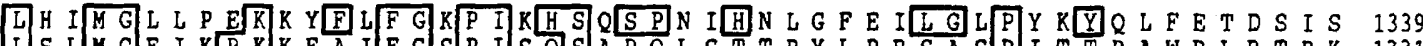
$\mathrm{L} S \mathrm{~S}$ L $\quad$ K G

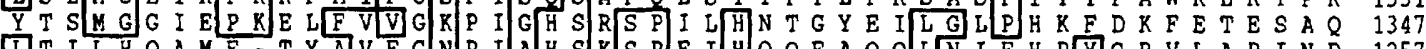
DT I L H Q A M E-T Y A VF G N P I A H S K S P F I H Q Q F A Q QLL I E H P Y G R V L A P I N D 1257

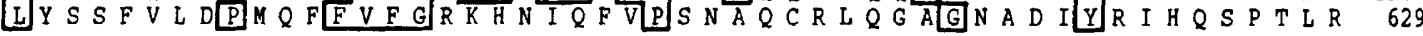

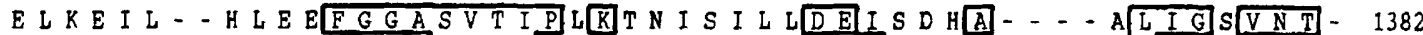
MCRSSS- ALLTSAAPSVT IRSSSTSCPF STRUPRKPR S E LLTOSFPCR 1379

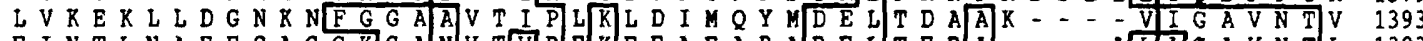

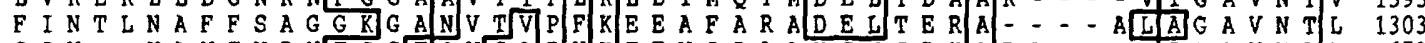

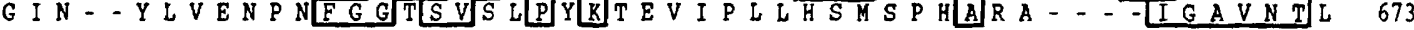

回T R T Y N

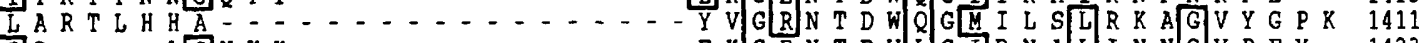

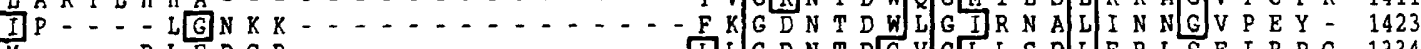

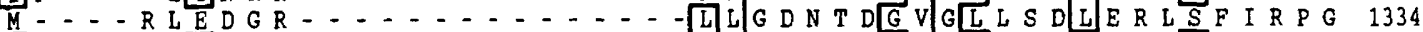

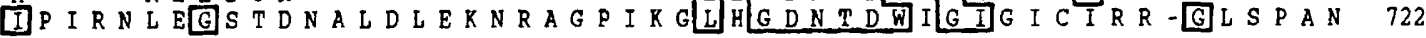

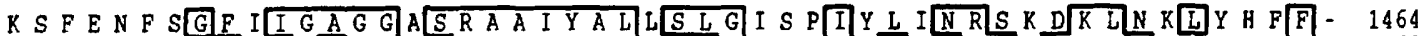

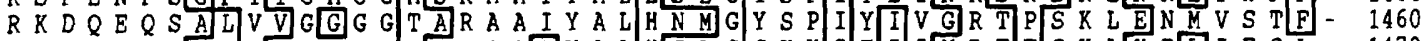

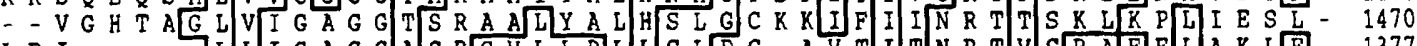

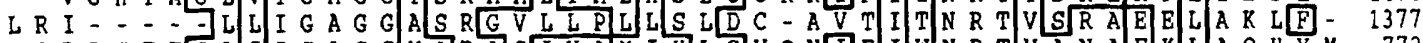

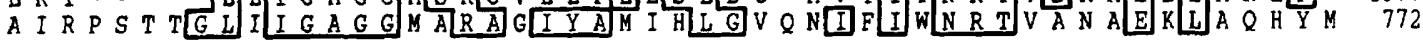

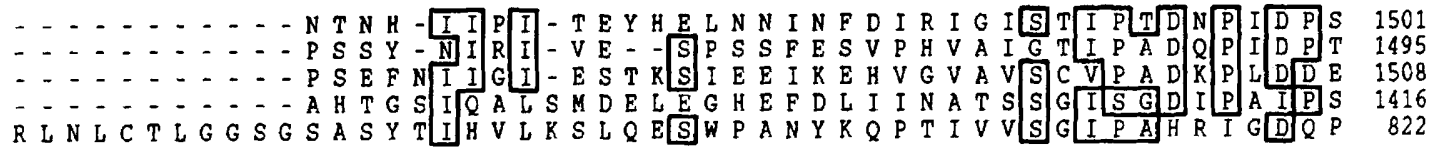

VLE I AKIFFNLKRKS SEG - ....... I F LDMAYG SNTTDDT- I I AKA 1539

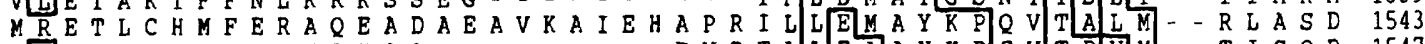

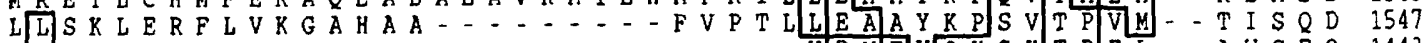

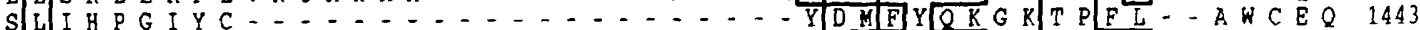

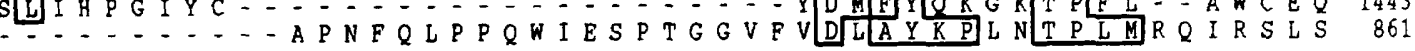

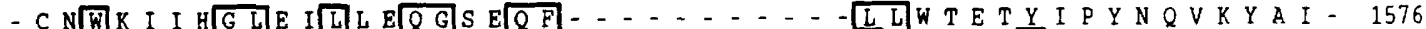

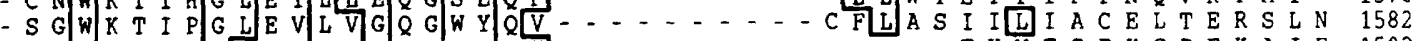

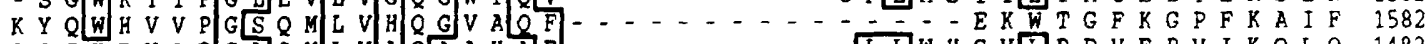

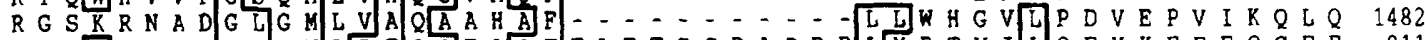

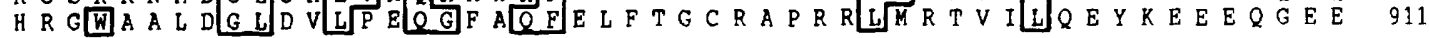

T G L

D A $V$ T K E ....................

E EU⿴囗十丁 $S$ A . . . . . . . . .

Y DQS A M R TRLENLDGQPM - -
1603

1588

1487 
cerevisiae has been shown to be under general amino acid control (Duncan et al., 1988).

The regulation of expression of the arom gene in $A$. nidulans is complicated by the presence of the inducible quinic acid utilization pathway which shares a common reaction with the aromatic amino acid biosynthetic pathway. Two of the intermediates from the prechorismate pathway, DHQ and DHS, are also substrates in the quinic acid utilization pathway (known as qut in $A$. nidulans), which is responsible for the catabolism of quinic acid to protocatechuate and is found in fungi such as $A$. nidulans and $N$. crassa but is absent from $S$. cerevisiae. The pentafunctional character of the AROM protein has been attributed to the need to channel DHQ and DHS in order to keep the intracellular pools of these metabolites separate (Giles, 1978). However, it has recently been demonstrated that the AROM protein is leaky in vivo and there is normally no significant channelling function (Lamb et al., 1991). However, under non-optimal conditions of nutrient and oxygen availability the channelling function may become significant so that a minimum flux through the aromatic biosynthetic pathway is maintained (Lamb et al., 1992). It has been proposed that expression of arom is linked to a starvation response for aromatic amino acids. The $P$. carinii arom locus seems to possess a GCN4 binding site indicating that it may be under general control and that the expression would be up-regulated in response to starvation for any amino acid, and thus would act to maintain a minimal level of aromatic amino acid biosynthesis even under conditions of nutrient depletion. However, it is not yet known whether $P$. carinii possesses a qut pathway.

\section{Confirmation that the cloned arom locus originates from} the $P$. carinii genome

The cloning strategy employed for the isolation of this AROM encoding gene combined with the unavoidable impurity of the $P$. carinii genomic DNA samples allowed for the possibility that the locus was not of $P$. carinii origin. Experiments involving the use of $\mathrm{pSB} 31$ as a probe for in situ hybridization and hybridization to $P$. carinii chromosomes were carried out to address this question.

DNA from a $P$. carinii enriched fraction extracted from infected rat lung was electrophoresed so that chromosomes in the size range $200 \mathrm{~kb}$ to $1 \mathrm{Mb}$ would be resolved. The karyotype obtained was considered to be that of $P$. carinii (Cushion et al., 1993). Under the CHEF conditions used, rat chromosomes were too large to be resolved and remained above the band of limiting mobility. Prior to extraction of $P$. carinii, impression smears of the infected lung were examined by light microscopy and no evidence of infection by any microbe other than $P$. carinii was observed. $S$. cerevisiae chromosomes were also separated by the CHEF procedure and transferred to a nylon membrane. The filters were probed with a ${ }^{32} \mathrm{P}$-labelled portion of the putative $P$. carinii arom locus. Under stringent conditions this fragment hybridized to one of the chromosomes of $P$. carinii (about $420 \mathrm{~kb}$ ) whereas there was no hybridization to the $S$. cerevisiae chromosomes (Fig. 4).

The same probe was biotinylated by means of a PCR reaction and was found to hybridize specifically to $P$. carinii DNA when used in an in situ hybridization experiment on sections of $P$. carinii infected rat lung. The thin walled, single nucleated trophozoite form of the organism develops through a series of stages involving thickening of the outer wall and division of the nucleus to form the mature cyst which contains up to eight intracystic bodies, each with a single nucleus. The sections from the in situ hybridization experiment were examined by light microscopy and the hybridization signal was characteristic of the distinctive arrangement of the nuclei of the intracystic bodies within the cysts (Wakefield et al., 1988). Signal was largely restricted to spherical bodies identified as cysts (Fig. 5). The EPSPS coding region from the $A$. nidulans arom gene was also biotin-labelled and used as a control in the in situ hybridization experiment on serial sections of $P$. carinii infected rat lung. No evidence of hybridization to $P$. carinii was observed. The background signal produced through the detection system for the biotinylated probes was assessed through the use of a control in which there was no probe added. The background signal was negligible.

\section{Analysis of the P. carinii AROM polypeptide}

The deduced amino acid sequence of the $P$. carinii AROM protein was compared with those from $A$. nidulans and $S$. cerevisiae and over the entire length there was significant similarity between the three sequences. The locations of the domains in the $P$. carinii protein, corresponding to the five enzyme activities, was determined by alignment of the amino acid sequence of the AROM protein with the sequences of the five monofunctional E. coli enzymes (Fig. 3). The order of the functional domains from the $\mathrm{N}$ - to the $\mathrm{C}$-terminus was DHQ synthase, EPSPS, shikimate kinase, DHQ dehydratase and shikimate dehydrogenase. The comparison also highlighted some regions with very little homology between the proteins, particularly in some of the interdomain regions, such as that between EPSPS and shikimate kinase. The alignment also includes the amino acid sequence of the qut repressor from $A$. nidulans, which is homologous to the three domains at the C- 
(a)

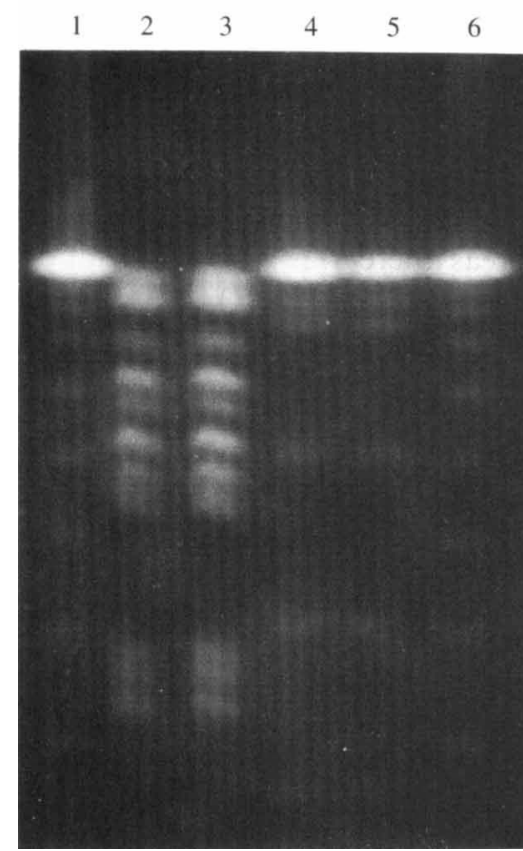

(b)

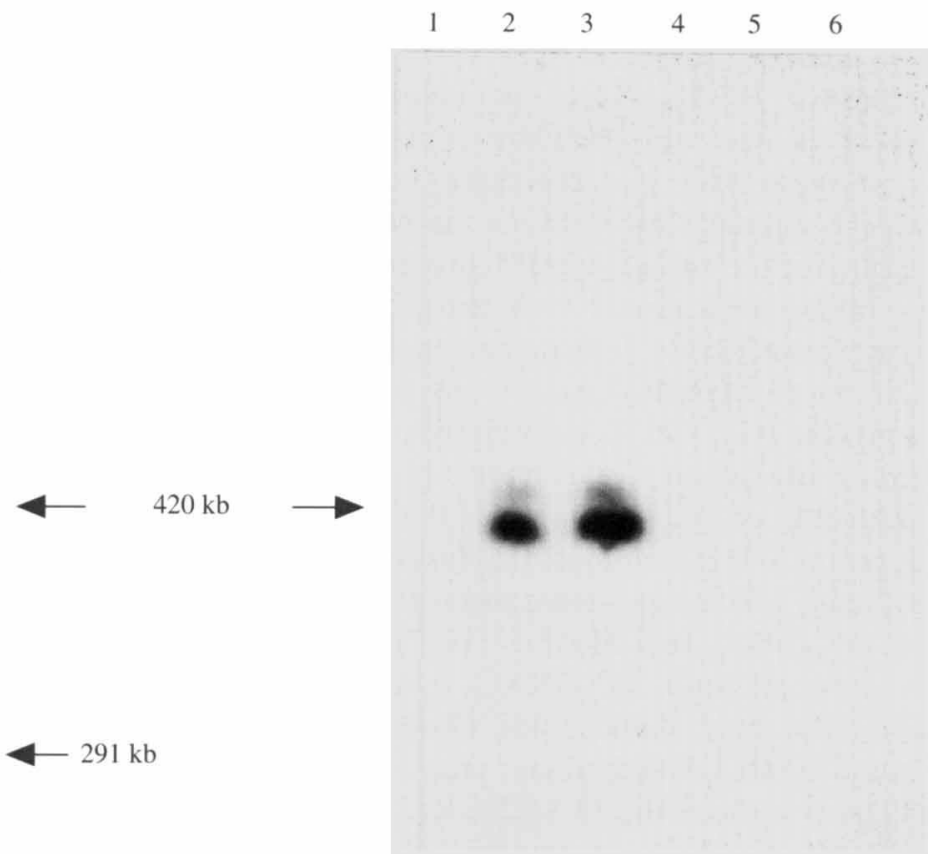

Fig. 4. (a) Electrophoretic karyotype of $P$. carinii from the rat host (lanes 2 and 3), S. cerevisiae (lanes 4 and 5) and $\lambda$ genome molecular size markers (lanes 1 and 6). The size of the smallest visible band $(291 \mathrm{~kb})$ in these markers is indicated and represents a concatamer of six $\lambda$ genomes. Each successive band represents an increase of $48.5 \mathrm{~kb}$. (b) Autoradiography after transfer of samples shown in $(a)$, probed with pSB31.

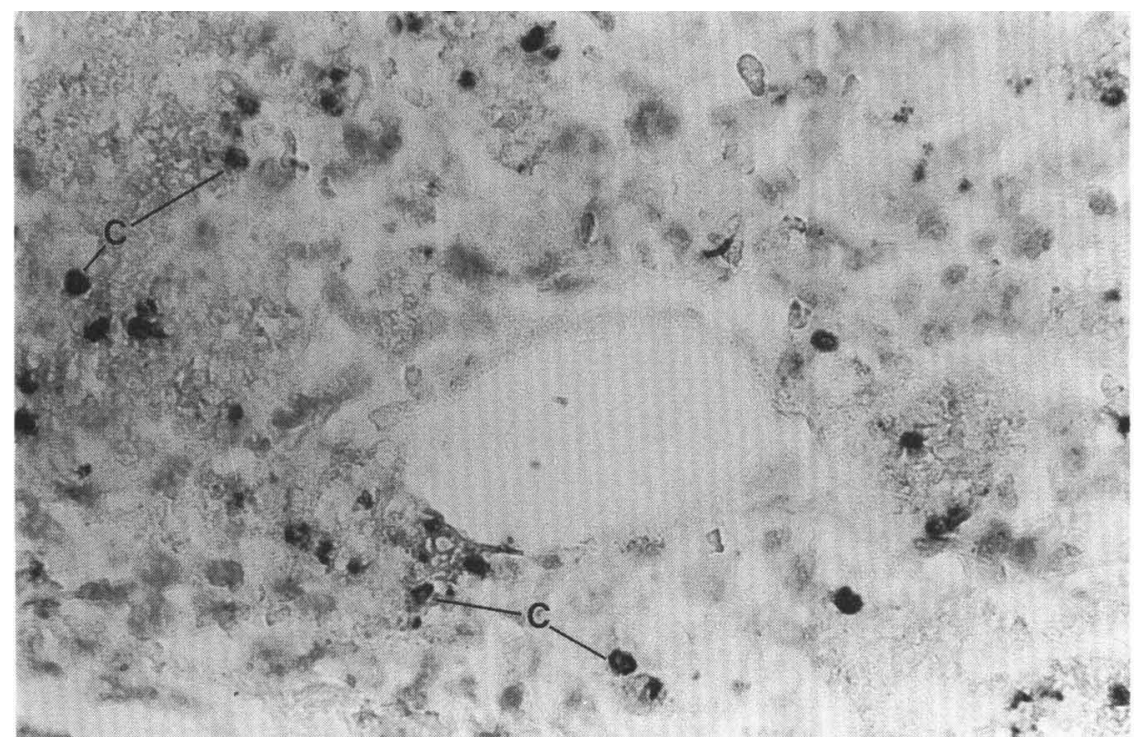

Fig. 5. In situ hybridization of a $P$. carinii arom biotin labelled probe (pSB31) to sections of $P$. carinii infected rat lung, showing hybridization signal in the distinct arrangement of the nuclei of the intracystic bodies within the $P$. carinii cysts (labelled ' $\mathrm{C}$ '), and absent from the surrounding rat tissue.

termini of the AROM proteins. This relationship is interesting in both functional and evolutionary terms. The repressor is thought to be capable of binding quinate, DHQ and DHS such that the binding of any of these would lead to the inactivation of the qut $R$ protein. However, in the absence of these metabolites the 
activator of the quinate utilization pathway (the qut $A$ protein) cannot bring about the induction of the enzymes required for quinate catabolism. The kinase activity of the qut repressor is thought to be involved in the inactivation of the activator (Hawkins et al., 1992). The homology between the qut repressor and AROM suggests an evolutionary link between the two genes.

Throughout the $P$. carinii AROM protein there are important amino acid motifs that are conserved in equivalent enzymes across fungal, bacterial and plant species. The motif LGNAGTA contains a universally conserved glycine (Gly ${ }^{96}$ in $E$. coli) implicated as being involved in the interaction of phosphoenolpyruvate with EPSPS (Padgette et al., 1991), and the universally contained group $\mathrm{DHR}$ contains the histidine residue (His ${ }^{385}$ in E. coli) which was shown to be at or near the active site of EPSPS by Huyhn (1987). A highly conserved sequence motif, GXGXXG, associated with polypeotides that bind dinucleotide (Rossman et al., 1974 ) is found in all DHQ synthase enzyme sequences

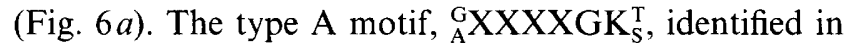
purine nucleotide binding proteins (Walker et al., 1982) is found in all shikimate kinase sequences (Fig. 6b).

The homology between the deduced amino acid sequence from the putative arom gene from $P$. carinii and the other AROM protein sequences together with the conservation of motifs identified as functionally important suggests very strongly that the gene encodes a functional AROM protein in vivo. The existence of an mRNA molecule that has been derived from the $P$. carinii arom gene further strengths this view. However, formal proof that the gene encodes a functional protein awaits the expression of the cloned $P$. carinii gene in a heterologous system such as $S$. cerevisiae, using $A R O 1$ mutants and demonstrating the ability of the $P$. carinii gene to complement such mutations.

\section{Multifunctional enzymes}

Multifunctional enzymes catalysing consecutive steps in metabolic pathways have been identified in a wide range of organisms but are especially common in lower eukaryotes. An example of this phenomenon has recently been discovered in $P$. carinii by Volpe et al. (1992), who cloned the folic acid synthesis gene (fas) which has two identifiable domains, 6-hydroxymethyl-7,8-dihydropterin pyrophosphokinase and dihydropteroate synthase. However, it was shown by Edman et al. (1989b) that the dihydrofolate reductase and thymidylate synthase genes of $P$. carinii were unfused, which differs from the protozoon arrangement but is in accord with the fungi.

The multifunctional AROM enzyme has been identified in all fungi investigated to date and also the unicellular green alga Euglena gracilis (Berlyn et al.,

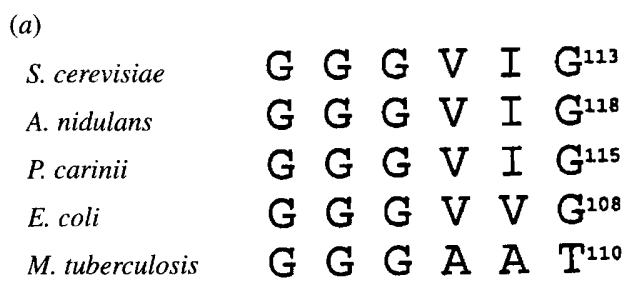

Motif associated with dinucleotide binding proteins

\section{$G \times G \times X G$}

(b)

\begin{tabular}{|c|c|c|c|c|c|c|c|c|}
\hline S. cerevisiae & $\mathbf{G}$ & $M$ & $\mathrm{R}$ & A & A & G & $\mathrm{K}$ & $T^{902}$ \\
\hline A. nidulans & G & $M$ & $R$ & $\mathrm{G}$ & A & G & $\mathrm{K}$ & $S^{878}$ \\
\hline P. carinii & $\mathbf{G}$ & $M$ & $\mathrm{R}$ & G & A & $\mathbf{G}$ & $\mathrm{K}$ & $T^{882}$ \\
\hline E. coli $(\operatorname{aroL})$ & $\mathbf{G}$ & $\mathrm{P}$ & R & $\mathbf{G}$ & C & G & $\mathrm{K}$ & $\mathrm{T}^{16}$ \\
\hline E. coli $(\operatorname{aroK})$ & $\mathbf{G}$ & $\mathrm{P}$ & $M$ & G & $\mathrm{C}$ & G & $\mathrm{K}$ & $S^{46}$ \\
\hline A. nidulans qutR & $\mathbf{G}$ & $I$ & $\mathrm{R}$ & G & $\mathrm{T}$ & G & $\mathrm{K}$ & $S^{132}$ \\
\hline $\begin{array}{l}\text { Type A motif associated } \\
\text { with proteins that bind } \\
\text { purine nucleotides }\end{array}$ & 2 & & & $x$ & $x$ & $\mathbf{C}$ & $\mathbf{K}$ & $\begin{array}{l}\mathbf{T} \\
\mathbf{S}\end{array}$ \\
\hline
\end{tabular}

Fig. 6. Motifs in the P. carinii arom complex. (a) Consensus sequence for a dinucleotide binding protein and corresponding motifs from DHQ synthase enzymes. The Mycobacterium tuberculosis sequence originates from Garbe et al. (1991). (b) The type A purine nucleotide binding motif and corresponding sequences from shikimate kinase enzymes. The aroL gene product is shikimate kinase II and aroK codes for shikimate kinase I (Løbner-Olesen \& Marinus, 1992). The A. nidulans qut repressor sequence shown is derived from the $\mathrm{N}$-terminal portion of this protein that is homologous to shikimate kinase.

1970). Thus the identification of the multifunctional protein in $P$. carinii is in accordance with recent evidence placing the organism in the fungal kingdom. The discovery of the pentafunctional AROM protein in $P$. carinii represents an extension in the knowledge of the metabolism of the organism. A high proportion of $P$. carinii genes cloned to date have had connections with folate metabolism, since many of the drugs currently in use act at this pathway. In addition to shedding light on the nature of $P$. carinii aromatic amino acid biosynthesis, the cloning of the $P$. carinii arom locus may suggest a novel approach to therapy. Since the mammalian hosts of $P$. carinii do not possess any of the enzymes of the prechorismate pathway, specific inhibitors of these enzymes might be antimicrobial without any adverse effects on the host. In addition, since the AROM protein is multifunctional it may present several targets for the design of inhibitors.

This research was funded by the Wellcome Trust (S. B. and A. G. A.), the MRC (S.E.P.), and the Royal Society (A.E.W.). We would also like to thank Dr A. R. Hawkins for supplying a clone carrying the 
EPSPS coding region from the arom gene of $A$. nidulans for use as a probe and $\operatorname{Dr}$ C. J. Delves for providing a $P$. carinii cDNA library.

\section{References}

Anton, I. A. \& Coggins, J. R. (1988). Sequencing and overexpression of the Escherichia coli aroE gene encoding shikimate dehydrogenase. Biochemical Journal 249, 319-326.

BaChmann, B. J. (1983). Linkage map of Escherichia coli, edition 7. Microbiological Reviews 47, 180-230.

Berlyn, M. B., Ahmed, S. I. \& Giles, N. H. (1970). Organization of polyaromatic biosynthetic enzymes in a variety of photosynthetic organisms. Journal of Bacteriology 104, 768-774.

Burns, J., Graham, A. F., Frank, C., Flemming, K. A., Evans, M. F. \& MCGEE, J. O'D. (1987). Detection of low copy papilloma virus DNA and mRNA in routine paraffin sections of cervix by nonisotopic in situ hybridisation. Journal of Clinical Pathology $\mathbf{4 0}$, $858-864$.

Charles, I. G., Keyte, J. W., Brammar, W. J., Smith, M. \& Hawkins, A. R. (1986). The isolation and nucleotide sequence of the complex AROM locus of Aspergillus nidulans. Nucleic Acids Research 14, 2201-2213.

Chaudhuri, S., Duncan, K., Graham, L. D. \& Coggins, J. R. (1991). Identification of the active-site lysine residues of two biosynthetic 3dehydroquinases. Biochemical Journal 275, 1-6.

Chen, E. Y. \& Seeburg, P. H. (1985). Supercoil sequencing: a fast and simple method for sequencing plasmid DNA. DNA 4, 165-170.

Cushion, M. T., Zhang, J., Kaselis, M., Giuntoli, D., Stringer, S. L. \& STRINGER, J. R. (1993). Evidence for two genetic variants of Pneumocystis carinii coinfecting laboratory rats. Journal of Clinical Microbiology 31, 1217-1223.

Devereux, J., Haeberli, P. \& Smithies, O. (1984). A comprehensive set of sequence analysis programs for the VAX. Nucleic Acids Research 12, 387-395.

Duncan, K., Lewendon, A. \& Coggins, J. R. (1984). The complete amino acid sequence of Escherichia coli 5-enolpyruvylshikimate-3phosphate synthase. FEBS Letters 170, 59-63.

Duncan, K., Chaudhuri, S., Campbell, M.S. \& Coggins, J. R. (1986). The overexpression and complete amino acid sequence of Escherichia coli 3-dehydroquinase. Biochemical Journal 238, 475-483.

Duncan, K., Edwards, R. M. \& Coggins, J. R. (1987). The pentafunctional arom enzyme of Saccharomyces cerevisiae is a mosaic of monofunctional domains. Biochemical Journal 246, $375-386$.

Duncan, K., Edwards, R. M. \& Coggins, J. R. (1988). The Saccharomyces cerevisiae ARO1 gene: an example of the co-ordinate regulation of five enzymes on a single pathway. FEBS Letters 241, $83-88$.

Dyer, M., Volpe, F., Delves, C. J., Somia, N., Burns, S. \& Scaife, J. G. (1992). Cloning and sequence of a $\beta$-tubulin cDNA from Pneumocystis carinii: possible implications for drug therapy. Molecular Microbiology 6, 991-1001.

Edman, J. C., Kovacs, J. A., Masur, H., Santi, D. V., Elwood, H. J. \& SogrN, M. L. (1988). Ribosomal RNA sequence shows Pneumocystis carinii to be a member of the fungi. Nature, London 334, 519-522.

Edman, J. C., Edman, U., CaO, M., Lundgren, B., Kovacs, J. A. \& SANTI, D. V. (1989a). Isolation and expression of the Pneumocystis carinii dihydrofolate reductase gene. Proceedings of the National Academy of Sciences of the United States of America 86, 8625-8629.

Edman, U., Edman, J. C., Lundgren, B. \& Santi, D. V. (1989 b). Isolation and expression of the Pneumocystis carinii thymidylate synthase gene. Proceedings of the National Academy of Sciences of the United States of America 86, 6503-6507.

EMANUEL, J. R. (1991). Simple and efficient system for synthesis of nonradioactive nucleic hybridization probes using PCR. Nucleic Acids Research 19, 2790.

FINK, G. R. (1986). Translational control of transcription in eukaryotes. Cell 45, 155-156.

Garbe, T., Servos, S., Hawkins, A. R., Dimitriadis, G., Young, D.,
Dougan, G. \& Charles I. (1991). The Mycobacterium tuberculosis shikimate pathway genes: evolutionary relationship between biosynthetic and catabolic 3-dehydroquinases. Molecular and General Genetics 228, 385-392.

GILES, N. H. (1978). The organization, function, and evolution of gene clusters in eukaryotes. American Naturalist 112, 641-657.

Giles, N. H., Case, M. E., Partridge, C. W. H. \& Ahmed, S. I. (1967). A gene cluster in Neurospora crassa coding for an aggregate of five aromatic synthetic enzymes. Proceedings of the National Academy of Sciences of the United States of America 58, 1453-1460.

Hawkins, A. R. (1987). The complex Arom locus of Aspergillus nidulans. Evidence for multiple gene fusions and convergent evolution. Current Genetics 11, 491-498.

Hawkins, A. R., Lamb, H. K. \& RoberTs, C. F. (1992). Structure of the Aspergillus nidulans qut repressor-encoding gene: implications for the regulation of transcription initiation. Gene 110, 109-114.

HuYNH, Q. K. (1987). Reaction of 5-enolpyruvylshikimate-3-phosphate synthase with diethyl pyrocarbonate: evidence for an essential histidine residue. Archives of Biochemistry and Biophysics 258, 233-239.

Kovacs, J. A., Powell, F., Edman, J. C., Lundgren, B., Martinez, A., Drew, B. \& Angus, C. W. (1993). Multiple genes encode the major surface glycoprotein of Pneumocystis carinii. Journal of Biological Chemistry 268, 60346040.

Lamb, H. K., Bagshaw, C. R. \& Hawkins, A. R. (1991). In vivo overproduction of the pentafunctional arom polypeptides in $\mathrm{As}$ pergillus nidulans affects metabolic flux in the quinate pathway. Molecular and General Genetics 227, 187-196.

Lamb, H. K., Van den Hombergh, P. T. W., Newton, G. H., Moore, J. D., Roberts, C. F. \& Hawkins, A. R. (1992). Differential flux through the quinate and shikimate pathways: implications for the channelling hypothesis. Biochemical Journal 284, 181-187.

LøBNer-Oleson, A. \& Marinus, M. G. (1992). Identification of the gene $(\operatorname{aro} K)$ encoding shikimic acid kinase I of Escherichia coli. Journal of Bacteriology 174, 525-529.

MillaR, G. \& Coggins, J. R. (1986). The complete amino acid sequence of 3-dehydroquinate synthase of Escherichia coli $\mathrm{K} 12$. FEBS Letters 200, 11-17.

Millar, G., Lewendon, A., Hunter, M. G. \& Coggins, J. R. (1986). The cloning and expression of the aroL gene from Escherichia coli K12. Biochemical Journal 237, 427-437.

Padgette, S. R., Biest Re, D., Gasser, C. S., Eichholtz, D. A., Frazier, R. B., Hironaka, C. M., Levine, E. B., Shah, D. M., FraLEY, R. T. \& KishorE, G. M. (1991). Site-directed mutagenesis of a conserved region of the 5-enolpyruvylshikimate-3-phosphate synthase active site. Journal of Biological Chemistry 266, 2236422369.

Peters, S. E., Wakefield, A. E., Baneru, S. \& Hopkin, J. M. (1992). Quantification of the detection of Pneumocystis carinii by DNA amplification, Molecular and Cellular Probes 6, 115-117.

Rossman, M. G., Moras, D. \& Olsen, K. W. (1974). Chemical and biological evolution of a nucleotide binding protein. Nature, London 250, 194-199.

Sambrook, J., Fritsch, E. F. \& Maniatis, T. (1989). Molecular Cloning: a Laboratory Manual, 2nd edn. Cold Spring Harbor, NY: Cold Spring Harbor Laboratory.

SANGer, F., Nicklen, S. \& Coulson, A. R. (1977). DNA sequencing with chain-terminating inhibitors. Proceedings of the National Academy of Sciences of the United States of America 74, 5463-5467.

Strauss, A. (1979). The genetic fine structure of the complex locus aro 3 involved in early aromatic amino acid biosynthesis in Schizosaccharomyces pombe. Molecular and General Genetics 172, 233-241.

TABOR, S. \& RiChARDSON, C. C. (1987). DNA sequence analysis with a modified bacteriophage T7 DNA polymerase. Proceedings of the National Academy of Sciences of the United States of America 84, 4767-4771.

Volpe, F., Dyer, M., Scaife, J. G., Darby, G., Stammers, D. K. \& DELVES, C. J. (1992). The multifunctional folic acid synthesis fas gene of Pneumocystis carinii appears to encode dihydropteroate synthase and hydroxymethyldihydropterin pyrophosphokinase. Gene 112, 213-218. 
Wakefield, A. E., Hopkin, J. M., Burns, J., Hipkiss, J. B., Stewart, T. J. \& Moxon, E. R. (1988). Cloning of DNA from Pneumocystis carinii. Journal of Infectious Diseases 158, 859-862.

Wakefield, A. E., Peters, S. E., Banerji, S., Bridge, P. D., Hall, G. S., Hawksworth, D. L., Guiver, L. A., Allen, A. G. \& Hopkin, J. M. (1992). Pneumocystis carinii shows DNA homology with the ustomycetous red yeast fungi. Molecular Microbiology 6, 1903-1911.

Walker, J. E., Saraste, M., Runswick, M. J. \& Gay, N. J. (1982).
Distantly related sequence in the $\alpha$ and $\beta$ subunits of ATP synthase, myosin, kinases, and other ATP requiring enzymes and a common nucleotide binding fold. EMBO Journal 1, 945-951.

YMPa-WONG, M. F., FonZI, W. A. \& SYPHERD, P. S. (1992). Fungusspecific translation elongation factor 3 gene present in Pneumocystis carinii. Infection and Immunity 60, 4140-4145.

ZHANG, J. \& STRINGER, J. R. (1993). Cloning and characterisation of an alpha-tubulin gene from rat derived $P$. carinii. Gene 123, 137-141. 